Jurnal Bidan Cerdas
e-ISSN: 2654-9352 dan p-ISSN: 2715-9965
Volume 3 Nomor 4, 2021, Halaman 199-207
DOI: 10.33860/jbc.v3i4.651
Website: http://jurnal.poltekkespalu.ac.id/JBC
Penerbit: Poltekk Kemenkes Palu

\title{
Analisis Kepuasan Pasien terhadap Pelayanan Kesehatan Ibu dan Anak (KIA) pada Masa Pandemi Covid-19
}

\author{
Metha Fahriani $₫$ D, Dewi Aprilia Ningsih I \\ Sekolah Tinggi Ilmu Kesehatan Tri Mandiri Sakti Bengkulu, Bengkulu, Indonesia \\ 凹Email: methafahriani42@gmail.com
}

\section{ARTICLE INFO \\ Article History: \\ Received: 2021-10-18 \\ Accepted: 2021-12-20 \\ Published: 2021-12-31}

\section{Kata Kunci:}

Kepuasan Pasien; Pelayanan KIA; Pandemi Covid-19;

\section{Keywords:}

Patient Satisfaction; Maternal Health and Child;

Covid-19 pandemic;

\begin{abstract}
ABSTRAK
Latar Belakang: Pada awal 2020, dunia dikejutkan dengan mewabahnya coronavirus disease 2019 (COVID-19). Penyebaran penyakit ini telah memberikan dampak luas salah satunya layanan yaitu Puskesmas, termasuk didalamnya adalah Pelayanan Kesehatan Ibu dan Anak (KIA). Tujuan: Menganalisis kepuasan pasien terhadap pelayanan kesehatan ibu dan anak (KIA) pada masa Pandemi Covid-19. Metode: Penelitian ini menggunakan analisis deskriptif dengan desain cross sectional. Pengambilan sampel dalam penelitian ini menggunakan accidental sampling dengan jumlah sampel yaitu 30 orang, pengumpulan data menggunakan kuesioner yang sudah di uji validitas dan reliabilitasnya. Analisis data menggunakan analisis univariat, analisis bivariat pearson chisquare, dan analisis multivariat regresi logistik. Hasil: uji Pearson ChiSquare diperoleh nilai $\rho$ value $<\alpha(0,05)$ pada variabel dimensi kehandalan $\rho: 0,019$, dimensi ketanggapan $\rho: 0,019$, dimensi jaminan $\rho: 0,009$, dimensi empati $\rho: 0,000$, dan variabel bukti langsung $\rho: 0,013$. Kesimpulan: variabel yang memiliki hubungan paling besar dengan kepuasan pasien terhadap pelayanan kesehatan Ibu dan Anak (KIA) pada Masa Pandemi Covid-19 yaitu Dimensi Empati (Emphaty), dengan nilai koefisien regresi $(\beta)$ yang paling besar. Diharapkan pelayanan KIA berfokus pada indikator kualitas pelayanan walaupun dalam keadaan Pandemi Covid-19.
\end{abstract}

\section{ABSTRACT}

Introduction: In early 2020, the world was shocked by the outbreak of the coronavirus disease 2019 (COVID-19). The spread of this disease has had a wide impact, one of which is services namely Puskesmas (Primary Health Care), including Maternal Health and Child. Purpose: to analyzing patient satisfaction with maternal and child health services during the Covid-19 Pandemic. Methods: This research uses descriftive analysis with cross sectional design. Sampling in this study using accidental sampling with a sample size of 30 people, collecting data using questionnaires that have been tested for validity and reliability. Data analysis used univariate, bivariate pearson chi-square, and multivariate logistic regression. Results: Pearson Chi-Square test obtained $\rho$-value $<\alpha(0,05)$ on variables dimensions of reliability $\rho: 0,019$, dimensions of responsiveness $\rho: 0,019$, dimensions of assurance $\rho: 0,009$, dimensions of empathy $\rho: 0,000$, and tanggibles variables $\rho: 0,013$. Conclusion: The variable that has the greatest relationship with patient satisfaction with maternal and child health services during the Covid-19 Pandemic is the Empathy Dimension, with largest regression coefficient ( $\beta$ ). It is hoped that health services will focus on service indicators even in the Covid-19 pandemic. 


\section{PENDAHULUAN}

Tujuan pembangunan kesehatan yang diselenggarakan oleh Puskesmas adalah mendukung tercapainya tujuan pembangunan kesehatan nasional yakni meningkatkan kesadaran, kemauan dan kemampuan hidup sehat bagi setiap orang yang bertempat tinggal di wilayah kerja Puskesmas agar terwujud derajat kesehatan yang setinggi-tingginya dalam rangka mewujudkan Indonesia Sehat. Fungsi Puskesmas adalah sebagai pusat penggerak pembangunan berwawasan kesehatan, pusat pemberdayaan masyarakat, serta pusat pelayanan kesehatan strata I yang meliputi pelayanan kesehatan perorangan \& pelayanan kesehatan masyarakat. (Sanah, N, 2017). Sebagai sebuah unit pelaksana teknis di Dinas Kesehatan, Puskesmas didorong untuk selalu meningkatkan kinerja sesuai dengan fungsi yang diembannya. Salah satu bentuk untuk mengevaluasi kinerja bidang kesehatan terutama Puskesmas yaitu dengan melihat tingkat kepuasan masyarakat terhadap Puskesmas (Ma'rufi, I.,Khoiri, A., Indrayani, R., \& Prasetyo, H., 2015). Untuk dapat memberikan pelayanan kesehatan secara menyeluruh (Comprehensive health care services) kepada seluruh masyarakat di wilayah kerjanya, Puskesmas menjalankan beberapa usaha pokok (basic health care services) yang meliputi beberapa program, salah satunya yaitu Program Kesehatan Ibu dan Anak (Sinaga, E.S, 2016).

Pada awal 2020, dunia dikejutkan dengan mewabahnya pneumonia baru yang bermula dari Wuhan, Provinsi Hubei yang kemudian menyebar dengan cepat ke lebih dari 190 negara dan teritori. Wabah ini diberi nama coronavirus disease 2019 (COVID19) yang disebabkan oleh Severe Acute Respiratory Syndrome Coronavirus-2 (SARSCoV-2). Penyebaran penyakit ini telah memberikan dampak luas secara sosial dan ekonomi (Susilo, A. et al, 2020). Pandemi Covid-19 telah merubah tatanan kehidupan baik pendidikan, ekonomi, pariwisata, sosial dan budaya termasuk sistem layanan kesehatan di Puskesmas. Berdasarkan data Kementerian Kesehatan tahun 2020, selama pandemi Covid-19 ini sebanyak $83,9 \%$ pelayanan kesehatan dasar tidak berjalan dengan optimal (Kemenkes, 2020). Dampak terhadap pelayanan kebidanan tersebut bisa berupa kurangnya pelayanan yang tepat, sesuai kebutuhan, dan komprehensif. Kualitas pelayanan erat kaitannya terhadap pemenuhan kebutuhan yang sesuai harapan pasien, terjangkau dan terstandar (Mawarti, F., Nuraini, F. \& Thamrin, M.H, 2016). Pelayanan asuhan kebidanan mempunyai tantangan yang lebih besar dengan adanya wabah Covid-19 termasuk bagaimana memberikan pelayanan sesuai standar dengan menjalankan prinsip penyelenggaraan pelayanan kebidanan pada masa Pandemi Covid-19. Kondisi ini setidaknya bermuara kepada kepuasan pasien terhadap mutu layanan yang diberikan fasilitas pelayanan Kesehatan Ibu dan Anak (KIA), seperti layanan terbatas, menimbulkan stigma terhadap petugas kesehatan, layanan "jemput bola" tidak berjalan efektif, kurang optimalnya inovasi layanan masa pandemi seperti pelayanan konsultasi berbasis teknologi dengan keterbatasan jaringan internet dan infrastrukturnya.

Tujuan penelitian ini adalah untuk menganalisis kepuasan pasien terhadap pelayanan kesehatan ibu dan anak (KIA) pada masa Pandemi Covid-19 yang meliputi dimensi kehandalan, dimensi ketanggapan, dimensi jaminan, dimensi empati, dan dimensi bukti langsung. Oleh karena itu peneliti tertarik untuk mengkaji lebih dalam mengenai kepuasan pasien terhadap pelayanan kesehatan ibu dan anak (KIA) pada masa Pandemi Covid-19. Urgensinya dilakukan penelitian ini adalah pelayanan Kesehatan Ibu dan Anak (KIA) merupakan bagian penting dari layanan kesehatan Puskesmas yang komprehensif mulai dari pra konsepsi, kehamilan, persalinan dan BBL, nifas, balita pra sekolah sampai dengan lansia yang dibutuhkan pemeriksaan rutin dan teratur dengan tujuan akhir yaitu menekan angka kematian ibu dan anak. 


\section{METODE PENELITIAN}

Penelitian ini menggunakan analisis deskriptif dengan desain cross sectional. Tempat penelitian dilakukan adalah di Puskesmas Sri Kuncoro, Kabupaten Bengkulu Tengah, Provinsi Bengkulu. Populasi pada penelitian ini adalah pasien yang berkunjung ke poli layanan KIA. Pengambilan sampel dalam penelitian ini menggunakan accidental sampling dengan jumlah sampel yaitu 30 orang. Variabel dependen yang diteliti adalah Kepuasan Pasien terhadap Pelayanan Kesehatan Ibu dan Anak (KIA) pada Masa Pandemi Covid-19, pasien dikategorikan puas dengan skor hasil ukur $>10-20$ dan kategori tidak puas dengan skor hasil ukur 1-9. Variabel independen yaitu dimensi kehandalan (hasil ukur baik jika skor $>15-30$ dan kurang baik jika skor 1-14), dimensi ketanggapan (hasil ukur baik jika skor $>13-25$ dan kurang baik jika skor 1-12), dimensi jaminan (hasil ukur baik jika skor $>15-30$ dan kurang baik jika skor 1-14), dimensi empati (hasil ukur baik jika skor > 17-35 dan kurang baik jika skor 1-16), dan dimensi bukti langsung (hasil ukur baik jika skor > 17-35 dan kurang baik jika skor 1-16). Jenis data yang digunakan dalam penelitian ini adalah data primer dan data sekunder. Data primer diperoleh melalui kuesioner yang berisi data demografi/karakteristik responden yaitu umur, Pendidikan, pekerjaan, dan jenis pembayaran. Kuesioner kepuasan pasien terhadap layanan Kesehatan ibu dan anak (KIA) dengan menggunakan skala gutmann (puas dan tidak puas) dan Kuesioner untuk mengukur dimensi kehandalan, dimensi ketanggapan, dimensi jaminan, dimensi empati, dan dimensi bukti langsung terdiri dari 31 item pertanyaan dengan menggunakan skala likert (sangat baik, baik, cukup, tidak baik, dan sangat tidak baik). Kuesioner tersebut sudah dilakukan uji validitas dan reliabilitasnya. Data sekunder berupa jumlah tenaga kesehatan dan jumlah penyintas pasien Covid-19 diperoleh dari Dinas Kesehatan Kabupaten Bengkulu Tengah dan daftar kunjungan pasien pada poli KIA diperoleh melalui Puskesmas Sri Kuncoro Bengkulu Tengah. Data dianalisis secara analisis univariat, bivariat, dan multivariat. Uji statistik yang digunakan adalah uji Chi-Square $\left(X^{2}\right)$ dan analisis regresi logistik ganda. Untuk mengetahui keeratan hubungan digunakan Contingency Coefficient (C).

\section{HASIL PENELITIAN}

Berdasarkan penelitian yang telah dilakukan, maka dapat disajikan hasil sebagai berikut:

Tabel 1. Distribusi Frequensi Karakteristik Individu responden

\begin{tabular}{lrc}
\hline \multicolumn{1}{c}{ Variabel } & Frekuensi & Persentase (\%) \\
\hline Kepuasan Pasien & & \\
$\quad$ Tidak Puas & 8 & 26,7 \\
$\quad$ Puas & 22 & 73,3 \\
Umur & & \\
20-29 tahun & 9 & 30,0 \\
30-39 tahun & 15 & 50,0 \\
$\quad 40-49$ tahun & 6 & 20,0 \\
Pendidikan & & \\
SD & 2 & 6,7 \\
SMP & 4 & 13,3 \\
SMA & 18 & 60,0 \\
PT & 6 & 20,0 \\
\hline Status Pekerjaan & & \\
$\quad$ Tidak Bekerja & 16 & 53,3 \\
Bekerja & 14 & 46,7 \\
\hline
\end{tabular}




\begin{tabular}{lcc}
\hline Variabel & Frekuensi & Persentase (\%) \\
\hline Jenis Pembayaran & & \\
Umum & 6 & 20,0 \\
BPJS/Asuransi Lainnya & 24 & 80,0 \\
\hline
\end{tabular}

Tabel 1 menunjukkan terdapat 8 orang responden $(26,7 \%)$ tidak puas terhadap pelayanan kesehatan ibu dan anak (KIA) pada masa pandemic Covid-19 dan terdapat 22 responden $(73,3 \%)$ menyatakan puas terhadap pelayanan kesehatan ibu dan anak (KIA) pada masa pandemic Covid-19. Terdapat 9 responden (30\%) dengan umur 2029 tahun, terdapat 15 responden (50\%) dengan umur 30-39 tahun, dan terdapat 6 responden (20\%) dengan umur 40-49 tahun. Terdapat 2 responden $(6,7 \%)$ dengan pendidikan SD, terdapat 4 responden $(13,3 \%)$ dengan pendidikan SMP, terdapat 18 responden $(60 \%)$ dengan pendidikan SMA, dan terdapat 6 responden $(20 \%)$ dengan pendidikan Perguruan Tinggi. Terdapat 16 responden $(53,3 \%)$ dengan status tidak bekerja dan terdapat 14 responden (46,7\%) dengan status bekerja. Terdapat 6 responden $(20 \%)$ dengan jenis pembayaran umum dan 24 responden $(80 \%)$ dengan jenis pembayaran BPJS/Asuransi Lainnya.

Tabel 2. Hubungan Dimensi Kehandalan, ketanggapan, jaminan/kepastian, empati, dan bukti langsung dengan Kepuasan Pasien terhadap Pelayanan Kesehatan lbu dan Anak (KIA) pada Masa Pandemi Covid-19

\begin{tabular}{|c|c|c|c|c|c|c|c|}
\hline \multirow{3}{*}{ Variabel } & \multicolumn{4}{|c|}{ Kepuasan Pasien } & \multirow{3}{*}{$\begin{array}{l}\text { Total } \\
\mathbf{n}\end{array}$} & \multirow{3}{*}{$\rho$ - value } & \multirow{3}{*}{$C$} \\
\hline & \multicolumn{2}{|c|}{ Tidak Puas } & \multicolumn{2}{|c|}{ Puas } & & & \\
\hline & n (8) & $\%$ & n (22) & $\%$ & & & \\
\hline \multicolumn{8}{|l|}{ Dimensi Kehandalan } \\
\hline Kurang Baik & 3 & 75,0 & 1 & 25,0 & 4 & \multirow{2}{*}{0,019} & \multirow{2}{*}{0,394} \\
\hline Baik & 5 & 19,0 & 21 & 81,0 & 26 & & \\
\hline \multicolumn{8}{|c|}{ Dimensi Ketanggapan } \\
\hline Kurang Baik & 5 & 56,0 & 4 & 44,0 & 9 & \multirow{2}{*}{0,019} & \multirow{2}{*}{0,393} \\
\hline Baik & 3 & 14,0 & 18 & 86,0 & 21 & & \\
\hline \multicolumn{8}{|c|}{ Dimensi Jaminan/Kepastian } \\
\hline Kurang Baik & 6 & 55,0 & 5 & 45,0 & 11 & \multirow{2}{*}{0,009} & \multirow{2}{*}{0,433} \\
\hline Baik & 2 & 11,0 & 17 & 89,0 & 19 & & \\
\hline \multicolumn{8}{|l|}{ Dimensi Empati } \\
\hline Kurang Baik & 5 & 83,0 & 1 & 17,0 & 6 & \multirow[t]{3}{*}{0,000} & \multirow[t]{2}{*}{0,539} \\
\hline Baik & 3 & 13,0 & 21 & 87,0 & 24 & & \\
\hline \multicolumn{7}{|l|}{ Bukti Langsung } & \\
\hline Kurang Baik & 4 & 67,0 & 2 & 33,0 & 6 & \multirow[t]{2}{*}{0,013} & \multirow[t]{2}{*}{0,412} \\
\hline Baik & 4 & 17,0 & 20 & 83,0 & 24 & & \\
\hline
\end{tabular}

Sumber: Data Primer, 2021

Tabel 2 menunjukkan hasil uji Chi-Square pada dimensi kehandalan dengan $p=0,019$, artinya ada hubungan antara dimensi kehandalan dengan kepuasan pasien terhadap pelayanan kesehatan Ibu dan Anak (KIA) pada Masa Pandemi Covid-19. Sedangkan hasil uji Contingency Coefficient didapat nilai $C=0,394$. Nilai $C$ tersebut dibandingkan dengan nilai $C_{\max }=\sqrt{\frac{m-1}{m}}$ dimana $\mathrm{m}$ adalah nilai terkecil dari baris atau kolom. Dalam hal ini nilai $\mathrm{m}=2$ maka nilai $C_{\max }=\sqrt{\frac{m-1}{m}}=\sqrt{\frac{2-1}{2}}=0,707$. Jadi nilai $\frac{C}{C_{\max }}=$ $\frac{0,394}{0,707}=0,55$, karena nilai ini terletak dalam interval 0,40-0,60 maka kategori hubungan sedang. 
Pada dimensi ketanggapan menunjukkan hasil uji Chi-Square dengan $p=0,019$, artinya ada hubungan antara dimensi ketanggapan dengan kepuasan pasien terhadap pelayanan kesehatan Ibu dan Anak (KIA) pada Masa Pandemi Covid-19. Sedangkan hasil uji Contingency Coefficient didapat nilai $C=0,393$. Nilai $C$ tersebut dibandingkan dengan nilai $C_{\max }=\sqrt{\frac{m-1}{m}}$ dimana m adalah nilai terkecil dari baris atau kolom. Dalam hal ini nilai $\mathrm{m}=2$ maka nilai $C_{\max }=\sqrt{\frac{m-1}{m}}=\sqrt{\frac{2-1}{2}}=0,707$. Jadi nilai $\frac{C}{C_{\max }}=\frac{0,393}{0,707}=0,55$, karena nilai ini terletak dalam interval 0,40-0,60 maka kategorii hubungan sedang.

Pada dimensi jaminan/kepastian menunjukkan hasil uji Chi-Square dengan $\mathrm{p}=$ 0,009, artinya ada hubungan antara dimensi Jaminan/Kepastian dengan kepuasan pasien terhadap pelayanan kesehatan Ibu dan Anak (KIA) pada Masa Pandemi Covid19. Sedangkan hasil uji Contingency Coefficient didapat nilai $C=0,433$. Nilai $C$ tersebut dibandingkan dengan nilai $C_{\max }=\sqrt{\frac{m-1}{m}}$ dimana $\mathrm{m}$ adalah nilai terkecil dari baris atau kolom. Dalam hal ini nilai $\mathrm{m}=2$ maka nilai $C_{\max }=\sqrt{\frac{m-1}{m}}=\sqrt{\frac{2-1}{2}}=0,707$. Jadi nilai $\frac{C}{C_{\max }}=$ $\frac{0,393}{0,707}=0,61$, karena nilai ini terletak dalam interval 0,60-0,80 maka kategori hubungan kuat.

Pada dimensi empati menunjukkan hasil uji Chi-Square dengan nilai $p=0,000$, artinya ada hubungan antara dimensi empati dengan kepuasan pasien terhadap pelayanan kesehatan Ibu dan Anak (KIA) pada Masa Pandemi Covid-19. Sedangkan hasil uji Contingency Coefficient didapat nilai $C=0,539$. Nilai $C$ tersebut dibandingkan dengan nilai $C_{\max }=\sqrt{\frac{m-1}{m}}$ dimana m adalah nilai terkecil dari baris atau kolom. Dalam hal ini nilai $\mathrm{m}=2$ maka nilai $C_{\max }=\sqrt{\frac{m-1}{m}}=\sqrt{\frac{2-1}{2}}=0,707$. Jadi nilai $\frac{C}{C_{\max }}=\frac{0,539}{0,707}=0,76$, karena nilai ini terletak dalam interval 0,60-0,80 maka kategori hubungan kuat.

Pada dimensi bukti langsung menunjukkan hasil uji Chi-Square dengan nilai $p=$ 0,013 , artinya ada hubungan antara dimensi bukti langsung dengan kepuasan pasien terhadap pelayanan kesehatan Ibu dan Anak (KIA) pada Masa Pandemi Covid-19. Sedangkan hasil uji Contingency Coefficient didapat nilai $C=0,412$. Nilai $C$ tersebut dibandingkan dengan nilai $C_{\max }=\sqrt{\frac{m-1}{m}}$ dimana m adalah nilai terkecil dari baris atau kolom. Dalam hal ini nilai $\mathrm{m}=2$ maka nilai $C_{\max }=\sqrt{\frac{m-1}{m}}=\sqrt{\frac{2-1}{2}}=0,707$. Jadi nilai $\frac{C}{C_{\max }}=$ $\frac{0,412}{0,707}=0,58$, karena nilai ini terletak dalam interval $0,40-0,60$ maka kategorii hubungan sedang. 
Tabel 3. Analisis Variabel Dominan Analisis kepuasan pasien terhadap pelayanan kesehatan Ibu dan Anak (KIA) pada Masa Pandemi Covid-19

\begin{tabular}{lcc}
\hline \multicolumn{1}{c}{ Variabel } & $\begin{array}{c}\text { Exp. B (Koef.Regresi } \\
\text { Logistic) }\end{array}$ & $\boldsymbol{P}$ \\
\hline Status Pekerjaan & 10.1 & 0.045 \\
Jenis Pembayaran & 10.0 & 0.025 \\
Dimensi Kehandalan (Reliability) & 12.6 & 0.044 \\
Dimensi ketanggapan (responsiveness) & 7.5 & 0.028 \\
Dimensi Jaminan Kepastian (Assurance) & 10.2 & 0.016 \\
Dimensi Empati (Emphaty) & 35.0 & 0.005 \\
Dimensi Bukti Langsung (Tangibles) & 10.0 & 0.025 \\
\hline
\end{tabular}

Tabel 3 menunjukkan ada tujuh variabel independen yang layak masuk kedalam model multivariat diantaranya adalah variabel status pekerjaan, jenis pembayaran, dimensi kehandalan (reliability), dimensi ketanggapan (responsiveness), dimensi jaminan kepastian (assurance), dimensi empati (emphaty), dan dimensi bukti langsung (tangibles). Dari ketujuh variabel tersebut hanya ada satu variabel yang memiliki hubungan paling besar dengan kepuasan pasien terhadap pelayanan KIA pada masa pandemi Covid-19 yaitu dimensi empati (emphaty), karena memiliki nilai koefisien regresi $(\beta)$ yang paling besar yaitu 35.0.

\section{PEMBAHASAN}

Dimensi kehandalan (Reliability) merupakan kemampuan Puskesmas untuk menghasilkan pelayanan kesehatan dengan apa yang dijanjikan (Ratnawati, L, 2015). Sebagian besar responden menilai baik terhadap dimensi kehandalan yaitu sebanyak 26 orang $(86,7 \%)$ indikator pertanyaan adalah berkaitan dengan petugas memberi informasi yang jelas mengenai pelayanan KIA terlebih saat kondisi pandemi Covid-19, Prosedur pelayanan selama Pandemi Covid-19 tidak berbelit-belit, Petugas mengingatkan pengunjung atau pasien untuk patuh terhadap protokol kesehatan selama Pandemi Covid-19, Petugas kesehatan menangani pasien dengan cepat, tepat dan teliti, Pasien selalu mendapatkan pelayanan prima oleh bidan walaupun saat kondisi pandemi Covid-19, sedangkan pada umumnya responden tidak puas dengan pertanyaan adanya pelayanan secara tidak langsung (dilakukan online) untuk konsultasi pelayanan KIA (Kesehatan Ibu dan Anak). Hasil ini sejalan dengan penelitian tentang kualitas layanan dan kepuasan pasien rawat inap pada Balai Pengobatan Santa Familia di Barong Tongkok Kabupaten Kutai Barat, dengan nilai pvalue sebesar 0,000 lebih kecil dari 0,05 berarti berpengaruh signifikan (Yanti, R., Jonathan, R., Lau, E.A, 2016). Penelitian lain yaitu Ismana (2015) di RSUD Arjawinangun Kabupaten Cirebon yang menyimpulkan ada hubungan yang bermakna antara Kehandalan (Reliability) dengan kepuasan pasein (Ismana, M.F, 2015)

Dimensi ketanggapan meliputi respon ataupun sikap petugas kesehatan dalam memberikan pelayanan kepada pasien, bagaimana kecepatan petugas dan ketanggapan petugas dalam menangani setiap pasiennya dalam penelitian ini adalah kemauan untuk merespon keinginan atau kebutuhan akan bantuan dari pasien, serta pelayanan yang cepat. Hal ini tercermin dari pertanyaan yang meliputi prosedur penerimaan pasien yang cepat dan tepat walaupun dalam keadaan pandemi Covid19 , tindakan yang cepat dan tepat pada saat melakukan pelayanan KIA di Puskesmas saat kondisi pandemi Covid-19, petugas terampil dalam melakukan pelayanan KIA di Puskesmas saat kondisi pandemi Covid-19, petugas siap membantu saat dibutuhkan walaupun dalam keadaan pandemi Covid-19, dan petugas segera menjelaskan bila pasien bertanya tentang kondisinya dan bayinya. Didapatkan data dari hasil penelitian 
bahwa sebagian besar responden menilai baik pada dimensi kehandalan yaitu 26 orang (86,7\%). Sejalan dengan penelitian Burhanudin (2016) di RSUD Syekh Yusuf Gowa yang menyimpulkan ada hubungan antara dimensi ketanggapan dengan kepuasan pasien (Burhanudin, N, 2016). Penelitian Nasyrah (2017) di Rumah Sakit Bhayangkara Makassar juga menyimpulkan ketanggapan berpengaruh positif dan signifikan secara parsial terhadap kepuasan pasien rawat inap di Rumah Sakit Bhayangkara Makassar (Nasyrah, Darwis, Hasmin, 2017).

Dimensi jaminan (Assurance) yaitu pengetahuan atau kesopanan petugas serta kemampuan mereka untuk menimbulkan kepercayaan dan keyakinan. Dalam penelitian ini meliputi Pasien yang berkunjung dilayani dengan baik walaupun dalam kondisi Pandemi Covid-19, Petugas kesehatan memberikan keterangan yang jelas resiko dan keuntungan sebelum dilakukan tindakan terutama dalam keadaan pandemi Covid-19, Petugas selalu memeriksa keadaan umum pasien (tekanan darah, nadi, pernafasan, suhu tubuh) terutama dalam keadaan pandemi Covid-19, Pelayanan yang sopan dan ramah walaupun dalam keadaan pandemi Covid-19, Petugas memanggil pasien sesuai dengan urutan atau nomor antrian pasien, dan Petugas kesehatan memiliki kemampuan yang baik sesuai dengan bidangnya.

Hasil penelitian menunjukkan bahwa semakin petugas kesehatan menunjukkan empati yang baik kepada pasien dalam pelayanan, maka semakin meningkat tingkat kepuasan pasien terhadap pelayanan kesehatan lbu dan Anak (KIA). Empati adalah keadaan psikologis yang mendalam, seseorang menempatkan pikiran dan perasaan diri sendiri ke dalam pikiran dan perasaan oranglain yang dikenal maupun orang yang tidak dikenal (Hasyim, M.M, 2012). Dalam kondisi Pandemi Covid-19 pelayanan kesehatan terkena dampak termasuk standar pelayanan yang dibatasi oleh protokol kesehatan, namun bagaimanapun juga pelayanan kesehatan yang prima harus tetap optimal dan menjadi prioritas utama dengan menunjukkan sikap empati. Empati merupakan dimensi penting dalam pelayanan kesehatan. Sejalan dengan penelitian yang dilakukan oleh Nur'aini (2019) di Rumah Sakit Demang Sepulau Raya Kabupaten Lampung Tengah. Yang menyimpulkan bahwa empati para medis berpengaruh terhadap kepuasan pasien (Nur'aini, 2019). Penelitian lain yang dilakukan (Perawati, 2021) di di RS Sri Pamela Tebing Tinggi menyimpulkan ada hubungan empati dengan kepuasaan Pasien di Instalasi Gawat Darurat RSU Sri Pamela Tebing Tinggi (Peratiwi, N,I., Ithing, Rahayu, S., \& Ambariani, 2021).

Kepuasan pasien adalah suatu keadaan dimana harapan pasien dipenuhi melalui kecepatan respon petugas dan pemberian kualitas pelayanan yang baik. Kepuasan pasien merupakan salah satu indikator penting dalam meningkatkan pelayanan kesehatan (Afrioza, S., \& Baidillah, I, 2021). Jadi dapat dipahami bahwa untuk dapat memberikan rasa kepuasan kepada pasien perlu upaya yang ekstra dalam mewujudkannya. Berupaya dalam artian bersungguh-sungguh memberikan seluruh potensi daya tanggap yang ada pada diri pegawai hanya untuk kepentingan pasien semata dengan tujuan agar tercapai kepuasan pasien (Nur'aini, 2019). Salah satu upaya untuk menciptakan kepuasan pasien terhadap layanan adalah penilain terhadap dimensi bukti langsung yang baik. Dimensi bukti langsung (Tangible) yaitu perbandingan antara harapan dengan kenyataan terhadap penampilan fasilitas fisik, peralatan, dan pegawai di Pelayanan Kesehatan (Puskesmas) Sri Kuncoro Bengkulu Tengah.

Dari hasil penelitian didapatkan sebagian besar responden yaitu 24 orang (80\%) dengan penilaian baik terhadap dimensi bukti langsung di Puskesmas Sri Kuncoro dan 22 orang (73,3\%) menyatakan puas dengan pelayanan kesehatan lbu dan Anak (KIA). Sejalan dengan Penelitian Lusiana dkk (2020) di RSUD Kota 
Tangerang, yang menyimpulkan bahwa terdapat hubungan signifikan antara bukti langsung kualitas pelayanan rawat inap terhadap tingkat kepuasan pasien (Lusiana, Nugrohowati, N., \& Wahyuningsih, S, 2020).

\section{SIMPULAN DAN SARAN}

Faktor yang berhubungan dengan kepuasan pasien terhadap pelayanan kesehatan ibu dan anak (KIA) pada masa Pandemi Covid-19 yaitu dimensi kehandalan, dimensi ketanggapan, dimensi jaminan, dimensi empati, dan variabel bukti langsung sedangkan faktor yang paling dominan yaitu variabel dimensi empati. Diharapkan bagi tenaga kesehatan bidan di Puskesmas Sri Kuncoro Bengkulu Tengah dapat terus meningkatkan indikator kualitas pelayanan walaupun dalam keadaan Pandemi Covid-19. Tenaga Kesehatan bidan harus memperhatikan dimensi kehandalan (reliability), dimensi ketanggapan (responsiveness), dimensi jaminan kepastian (assurance), dimensi empati (emphaty), dan dimensi bukti langsung (tangibles) saat memberikan layanan kebidanan pada Kesehatan Ibu dan Anak (KIA).

\section{UCAPAN TERIMA KASIH}

Terimakasih kepada Direktorat Riset dan Pengabdian Masyarakat, Deputi Bidang Penguatan Riset dan Pengembangan Kementerian Riset dan Teknologi/ Badan Riset dan Inovasi Nasional yang telah memberikan dana hibah Penelitian Dosen Pemula Tahun Anggaran 2020 dengan kontrak penelitian Nomor: 1201/SP2H/LL2/2021 tanggal 19 April 2021.

\section{DAFTAR PUSTAKA}

Afrioza, S., \& Baidillah, I. (2021). Hubungan tingkat kepuasan pasien terhadap pelayanan kesehatan di Puskesmas Sepatan. Journal of Nursing Practice and Education, Vol. 01 No. 02., 169-180. https://ejournal.stikku.ac.id/index.php/jnpe/ article/view/305/219.

Burhanudin, N. (2016). Hubungan mutu pelayanan kesehatan dengan kepuasan pasien RSUD Syekh Yusuf Gowa. Jurnal MKMI, Vol 12 No.1, 41-46. https://journal.unhas.ac.id/index.php/mkmi/article/view/552

Hasyim, M.M. (2012). Cerita bertema moral dan Empati Remaja Awal. Jurnal Psikologi. Vol. 7, No. 1. 501-508. https://jurnal.unmer.ac.id/index.php/jpt/article/view/203

Ismana, M.F. (2015). Hubungan antara lima dimensi mutu pelayanan rawat jalan dengan kepuasan pasien di RSUD Arjawinangun Kabupaten Cirebon. Jurnal Kesehatan, Vol 6, No. 2., 708-717. http://jurnal.stikescirebon.ac.id/index.php/kesehatan/article/view/ $151 / 96$.

Lusiana, Nugrohowati, N., \& Wahyuningsih, S. (2020). Analisis hubungan kualitas pelayanan terhadap kepuasan pasien rawat inap penyakit dalam di RSUD Kota Tangerang. Seminar Nasional Riset Kedokteran (pp. 80-85). Jakarta: SENSORIK. https://conference.upnvj.ac.id/index.php/sensorik/article/view/438/591

Ma'rufi, I.,Khoiri, A., Indrayani, R., \& Prasetyo, H. (2015). Kepuasan Masyarakat terhadap Pelayanan Puskesmas: Kajian Kualitatif Kultur Medis, Standarisasi Mutu, Konsep Puskesmas dan Relasi Dokter Pasien di Kabupaten Jember. Jurnal IImu Kesehatan Masyarakat, 72-89. https://jurnal.unej.ac.id/index.php/IKESMA/article/view/4352

Mawarti, F., Nuraini, F. \& Thamrin, M.H. (2016). Analisis Kualitas Pelayanan Puskesmas Terhadap Kepuasan Ibu Hamil Di Kota Pangkalpinang. Jurnal Kedokteran dan Kesehatan, 363-371. https://ejournal.unsri.ac.id/index.php/jkk/article/view/2854

Nasyrah, Darwis, Hasmin. (2017). Analisis pengaruh dimensi kualitas pelayanan terhadap kepuasan pasien rawat inap di Rumah Sakit Bhayangkara Makassar. Jurnal Mirai Management, Volume 2 Nomor 1., 133-148. https://journal.stieamkop.ac.id/index.php/ mirai/article/view/45/44.

Nur'aini. (2019). Pengaruh daya tanggap dan empati paramedis terhadap kepuasan pasien di 
Rumah Sakit Demang Sepulau Raya Kabupaten Lampung Tengah. Jurnal Simplex Vol. $\quad 2, \quad$ No. $\quad 1, \quad 80-89$. https://fe.ummetro.ac.id/ejournal/index.php/JS/article/download/345/237

Peratiwi, N,I., Ithing, Rahayu, S., \& Ambariani. (2021). Hubungan Empati dengan kepuasan pasien di Instalasi Gawat Darurat Rumah Sakit Umum Sri Pamela Tebing Tinggi. Jurnal Kesehatan dan Kebidanan, 118-127. Vol.X. No. 2 https://smrh.ejournal.id/Jkk/article/view/147/107

Ratnawati, L. (2015). Hubungan antara Persepsi Mutu Pelayanan dengan Tingkat Kepuasan Pasien KIA Puskesmas Ngesrep Kota Semarang. Skripsi. Universitas Negeri Semarang. http://lib.unnes.ac.id/23495/

Sanah, N. (2017). Pelaksanaan fungsi Puskesmas (Pusat Kesehatan Masyarakat) dalam meningkatkan kualitas pelayanan kesehatan di Kecamatan Long Kali Kabupaten Paser. eJournal IImu Pemerintahan, 305-314. https://ejournal.ip.fisipunmul.ac.id/site/wp-content/uploads/2017/03/Nor\%20Sanah\%20(03-01-17-09-1545).pdf

Sinaga, E.S. (2016). Hubungan pelayanan KIA/KB dengan kepuasan pasien di Puskesmas Pulo Brayan Medan Barat. Scienta Journal STIKES Prima Jambi, 99-107. http://ejournal.unaja.ac.id/index.php/SCJ/article/view/199

Susilo, A. et al. (2020). Coronavirus Disease 2019:Tinjauan Literatur Terkini. Jurnal Penyakit Dalam Indonesia, Vo. 7, No. $\quad$ 1., $45-67$. http://jurnalpenyakitdalam.ui.ac.id/index.php/jpdi/article/view/415

Yanti, R., Jonathan, R., Lau, E.A. (2016). Kualitas layanan dan kepuasan pasien rawat inap pada Balai Pengobatan Santa Familia di Barong Tongkok Kabupaten Kutai Barat. Jurnal Ekonomia, Vo. 5, No. 2., 1-7. http://ejurnal.untagsmd.ac.id/index.php/EKM/article/view/1920 